\title{
SEMANTIC WEB FOR E-LEARNING BOTTLENECKS: DISORIENTATION AND COGNITIVE OVERLOAD
}

\author{
Mehmet FIRAT ${ }^{1}$ and Abdullah KUZU² \\ ${ }^{1}$ Anadolu University, Open Education Faculty, Eskisehir, TURKEY \\ mfirateanadolu.edu.tr \\ ${ }^{2}$ Anadolu University, Faculty of Education, Eskisehir, TURKEY \\ akuzu@anadolu.edu.tr
}

\begin{abstract}
Web environments provide learners with a great amount of information and various environments and opportunities that they can use to navigate, yet problems may occur as a result of the abundant choices and flexibility provided by these Web-based environments. Among these problems disorientation and cognitive overload in hypermedia are important bottlenecks. But recently emerging semantic web is considered as an important solution point for these problems. The purpose of this study is to evaluate the potentials to decrease or overcome the problems related to disorientation and cognitive overload of Semantic Web substructure and its components in the Web environment. For this purpose, this study first discus Semantic Web, disorientation in Hypermedia, and cognitive overload. Following this, Semantic Web components and the features of these components are examined to evaluate the potentials to decrease or overcome disorientation and cognitive overload in hypermedia learning environments.
\end{abstract}

\section{KEYWORDS}

Web Semantics, e-learning, cognitive overload, disorientation

\section{INTRODUCTION}

Developments in computer technologies led to fundamental changes in traditional teaching and learning environments. Web-based learning environments have the potential to provide learners with a great amount of information and various environments and opportunities that they can use to navigate, yet certain problems occur due to the abundant choices and flexibility provided by these Web-based environments. The flexibilities provided by Web-based learning environments may cause significant problems for learners because flexibility increases complexity. Among the most important problems that occur due to this complexity of hypermedia are those related to cognitive overload $[1,2,3,4]$ and disorientation in hypermedia $[5,6,7,8,4]$.

This study first mentions Semantic Web defined as the new generation of the Web, disorientation in Hypermedia, and cognitive overload. Following this, Semantic Web components and the features of these components are examined. In the end, the study evaluates the potentials of the Semantic Web to decrease or overcome disorientation and cognitive overload in hypermedia. 
International Journal of Web \& Semantic Technology (IJWesT) Vol.2, No.4, October 2011

\subsection{Cognitive Overload}

The concept of cognitive overload depends on the theory of cognitive load. The theory of cognitive load first appeared in the 1980s and was developed and shaped through research conducted during the next decade. This approach is related to educational inferences made from the relationship between cognitive structure and the structure of information. According to the cognitive load theory, learning in effective educational materials is facilitated when cognitive sources are directed to learning activities rather than to the preconditions of learners [9].

Cognitive load can be defined as mental sources used in a memory that works simultaneously. seven plus or minus two has been a commonly used guideline for gauging how many chunks of new information should be presented at one time in learning and performance situations and this often cited as the limit of working memory [10]. People can process an average of seven units of information in average at a time in a working memory [11]; that is, as the amount of information processed in a memory working simultaneously due to its limited cognitive capacity increases, the cognitive load will increase as well. In general, there are two types of cognitive load [12]: germane load/effective load and extraneous load/ineffective load.

The germane load results from the difficulty of the content being learned. If the learner meets a complex content, his or her germane cognitive load will be high. Extraneous load is related to the design of the environment in which information is presented. When the environment includes additional information, which is inappropriate, and which impacts information processing, the extraneous load will be high. If both the germane load and the extraneous load are at a level higher than the limitedness of the working memory, cognitive overload occurs. Since the germane load and the extraneous load are added to each other, according to the cognitive load theory, the extraneous/ineffective load should be decreased and the germane/effective load be increased [13].

According to the cognitive load theory, the limitedness of the working memory can be eliminated by encoding different information components as one in cognitive schema, by the multiple presentation method or by automation rules [14]. Besides environmental interaction, the activities learners participate in and in what ways information is transmitted to learners may influence cognitive load. If this loading is higher than necessary and makes it difficult to create a scheme, then it is called cognitive overload [13].

Although hypermedia has provided a number of opportunities to increase the richness of user interfaces, it has also caused over-crowdedness and complexities that result from abundant information in the interface. The freedom provided by hypermedia for the user to control the interaction with the system may lead to cognitive overload [15] because the cognitive sources that should be allocated to meta-cognition and executive skills necessary for navigation in hypermedia will be used for other subjects. Gathering a large amount of irrelevant information can negatively influence the process of information processing and cause cognitive overload. In addition, students cognitively overloaded among different choices due to the intensity of complex information in hypermedia may not know where they are, where they came from, and where they are going to go, which means they get disoriented [7].

\subsection{Disorientation}

Disorientation is defined as a situation in which due to cognitive overload and to the complexity of the environment, learners do not know where they are or how they can reach the place they want $[16,17]$. In other words, disorientation means that learners are not aware of their places within the whole structure and do not know how they have reached that place and how and where they will go. 
International Journal of Web \& Semantic Technology (IJWesT) Vol.2, No.4, October 2011

Although disorientation is also known as lostness in related literature, the former is more frequently used. The reason is that the word 'disorientation' has a more comprehensive meaning. The word 'lostness' refers only to getting lost or losing one's way, while the word 'disorientation' not only means getting lost in an environment but also covers the inability of individuals to direct themselves in such a situation.

Almost all users navigating in a Web environment to search for information are likely to encounter with the problem of disorientation. Users should be able to answer such questions as "Where am I?", "Where do I want to go?", "Am I on the right way?" and "How will I know I will get to where I want?" so that they can know where they are within the whole system in a dynamic environment like the Internet and that they can take action appropriate to their goals [6]. Users who cannot find answers to such questions are said to have got lost.

The disorientation problem in hypermedia-based learning environments and other undesired problems that result from disorientation can be considered in such three categories as navigational disorientation, the problem of abundance of choices, and the phenomenon of art museum [18]. Navigation disorientation is related to the fact that by following the nodes, users navigate in the environment in repeated cycles without achieving effective results. The problem of abundance of choices means that users know they are wasting their time, that they feel lost, that they lose their way by following various directions provided by the environment, and that they thus wander astray from the main subject. As for the phenomenon of art museum, it refers to the problems arising from the fact that users navigate in the hypermedia in an uncontrolled manner in order to reach information [19]. This situation is similar to the situation of a person who goes around in an art museum spending the whole day without being interested in any specific shape or model. On the second day, this person is likely to be unable to define any of the drawings or shapes he or she saw in the museum the previous day.

When studies conducted to decrease or overcome the problem of disorientation are examined, it is seen that these studies generally focus on navigational tools [5]. However, it is not possible to expect navigational tools like site maps that we place within an environment prevent users from getting lost [6]. The reason is that people show effort to give meaning to information found in the Web environment that allows high level of user control today. This leads to cognitive overload, disorientation and especially results in a need for renovation related to Web components.

\subsection{Semantic Web or Web 3.0}

In order to help users reach the necessary information in the Web environment, meta-search engines that gather and present all the results obtained from various databases, search engines, and even from a number of search engines have been developed. In addition, there are different strategies and techniques developed to find information via these search tools. However, helping the user reach the information appropriate to his or her goal still constitutes an important problem. For example, as a result of keyword-based searches through global search engines like Google and Yahoo, the user is likely to reach thousands of sources of information, either relevant or irrelevant [20].

HTML and World Wide Web have made it quite easy to create and share information that people can read, change and publish and have played a significant role in the development of the Web. However, in this system, people try to understand what the information is about and whether it is appropriate to the goals or not [21]. Therefore, the responsibility to decide on the meaningfulness of the information is on the user rather than on the computer. This system has reached its boundaries of its natural capacity due to the increasing number of users and to the increasing amount of information. Nevertheless, it is seen that Semantic Web that focuses on the role of 
Semantics - defined as the new generation of the Web - in automatic approaches has occurred to benefit from the Web sources [22].

According to Tim Berners-Lee (1998), who is considered the founder of the Web, "Web was designed not only for human-human interaction but also as an information area which machines would contribute to."(s.1). However, it is seen that so far, computers had a passive role in giving meaning to the information found in the Web environment. The language of HTML, which is a basic way of presenting information in hypermedia, was developed in a way that people would understand it. When an HTML page is examined, it can be seen that the page is made up of a title and paragraphs and that several additions like pictures, audios, videos, and animations can be made into the page. Such a design of a page has a relation with what the page will look like in the Web environment rather than with giving meaning to the information presented.

In order to meet such needs in the Web environment and to assign an active role to computers for giving meaning to information, a group of researchers, under the leadership of Tim Berners-Lee, carried out a study called "The Semantic Web" in 2001. The study paved the way for a new area called "Semantic Web" that required the restructuring of the Web. Here Semantic Web was defined as a data-Web similar to a global database in certain respects (s.1). In other words, Semantic Web helps aggregate information scattered in different areas in the Web environment like the pieces of a jigsaw puzzle - and then combines and gives meaning to the information to reutilize it. Semantic web is not a new and different web, but a follow-up of today's web that enables computers and people to work together in order to give meaning to information in the Web environment [23].

\subsection{Significance and Purpose of Study}

Information has gained more value with Web technologies than ever before. Furthermore, functions such as reaching information quickly and structuring, managing and distributing it have also gained as much value as the information itself. The value of the processes of interaction with information has resulted in important needs in the areas of press, politics, security and economy as well as in the area of education. Among these needs, the most important one is reaching the correct, reliable and up-to-date information quickly. Therefore, it is of great significance to investigate the potential of this new generation of the Web sub-structure and its components defined as Semantic Web - to decrease or overcome the problems of cognitive overload and disorientation, the two most important bottlenecks in fast and effective access to information on the Web.

The purpose of this descriptive study is to the potentials of Semantic Web sub-structure and its components to decrease or overcome the problems of cognitive overload in the Web environment.

\section{Examination Of Semantic Web In Terms Of Cognitive OVERload AND DISORIENTATION}

There are an increasing number of studies conducted on the components of Semantic Web and on related applications. The primary goal of these studies was to develop the standards and technologies that would help computers understand and process the well-defined and associated data in the web environment. For this purpose, several institutions such as the W3C (World Wide Web Consortium) an independent institution established in the leadership of Tim Berners-Lee, Massachusetts Technology Institution, Hewlett-Packard (HP), International Business Machines (IBM) and other organizations within the user base are going on their research on developing technology and on determining the standards related to Semantic Web. 


\subsection{Semantic Web Components}

When the proliferation process of the Web throughout the world and the Web components are examined, systematic advances and improvements were revealed. First, HTML informationdisplay that people could understand was developed. Later, to share this information, http protocol was developed. Following the sudden increase in the amount of the information shared in the Web environment, the languages of XML, RDF and OWL were developed to give meaning to the information, that is, to add the structural information and the meaning of the information [23]. The Semantic Web standards established by the W3C and approved throughout the world include the tools of XML, XML Schema, RDF, RDF Schema, OWL and URIs [24]. Each of these technologies is described below in Figure 1.

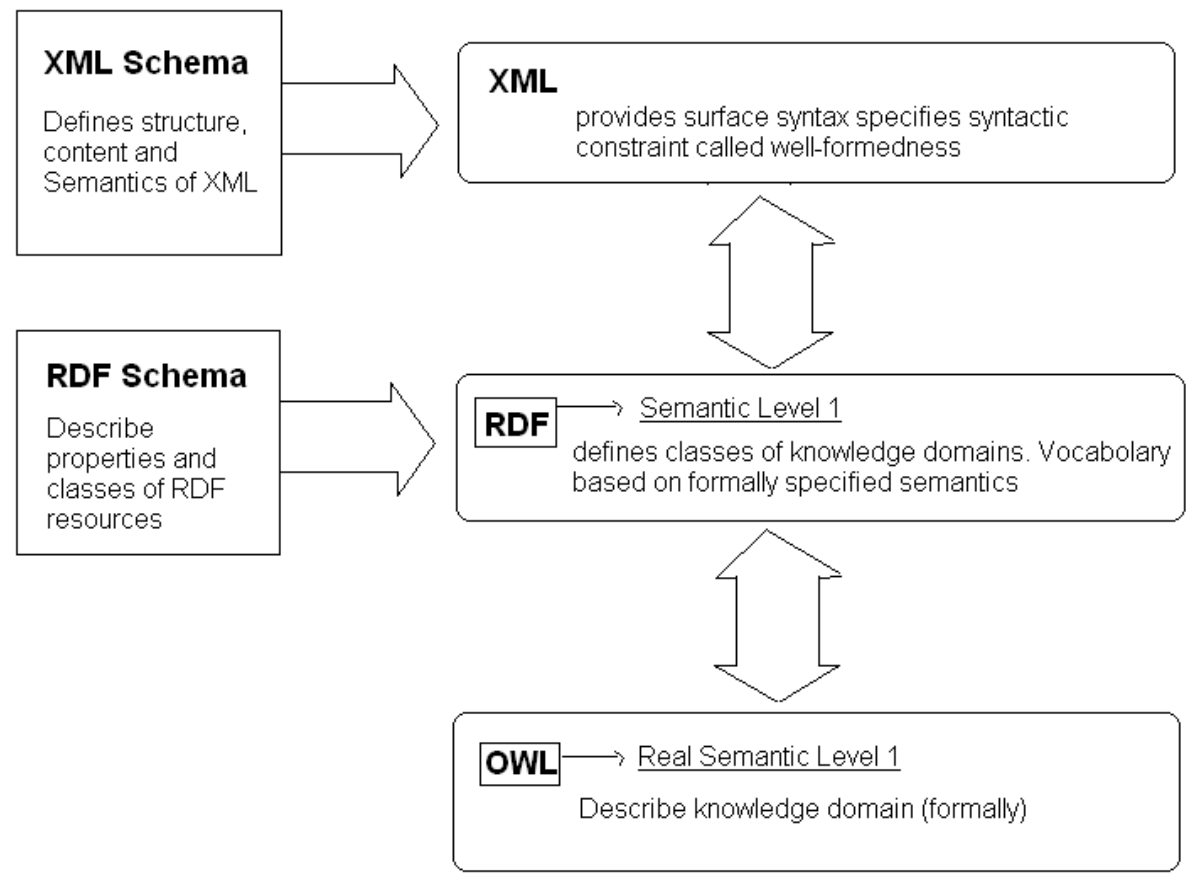

Figure 1. Semantic Technologies

\subsubsection{XML (EXtensible Markup Language)}

XML, which is an "extensible markup language", is a language used to help create documents that both people and computers can easily read. Tim Berners Lee, the designer of HTML, designed this language, for whose arrangement the $\mathrm{W} 3 \mathrm{C}$ is responsible. Here in below $\mathrm{XML}$ structure as a family tree showed in Figure 2.

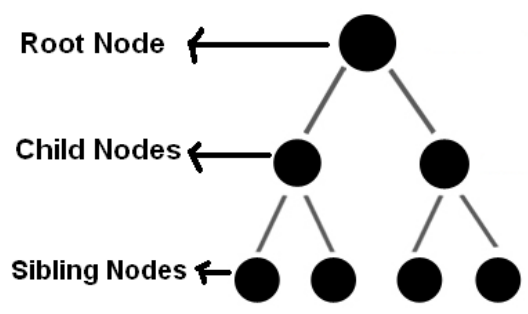

Figure 2. XML structure as family tree 


\subsubsection{XML Schema}

XML Schema is a language developed to define the rules that XML files should obey. XML Schema helps check whether XML file is well-formed or not. In addition, XML Schema determines the rules regarding which elements this file will include, which elements will be found in this element, and which qualities will be added to each element. In short, XML Schema facilitates the syntax recognition for XML files. A list of XML Schema data types showed below in Figure 3.

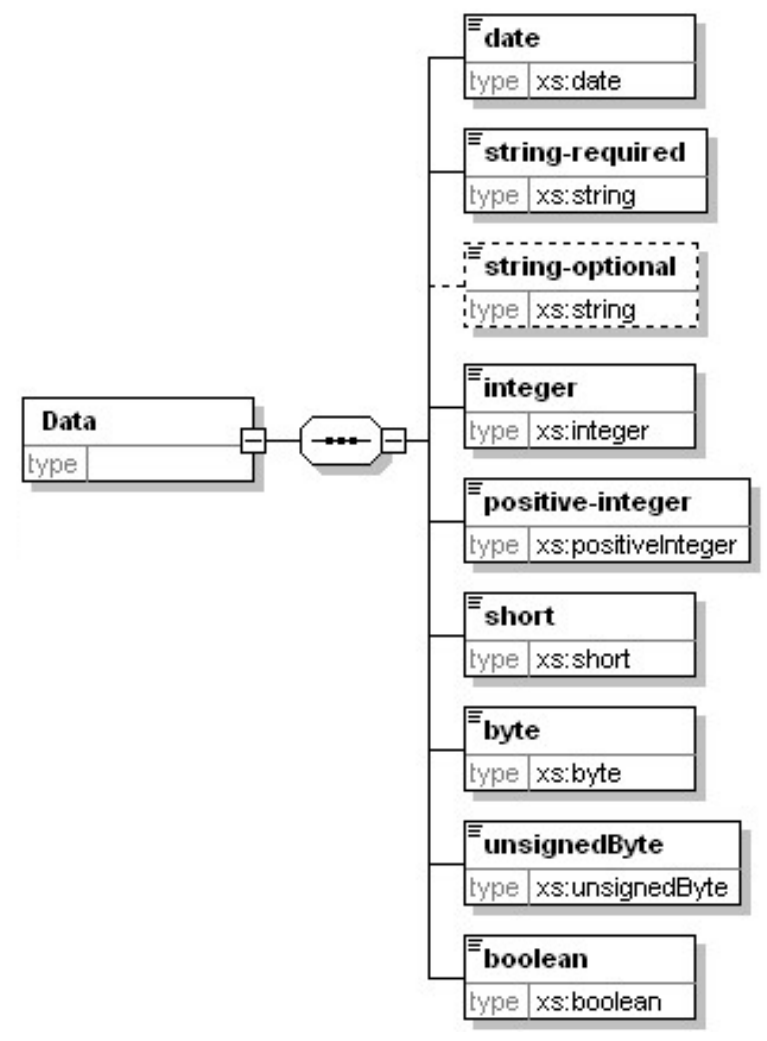

Figure 3. XML Schema data types

\subsubsection{RDF (Resource Description Framework)}

RDF, which is resource description framework, is a series of standards defined by W3C in 1999. At the same time, RDF constitutes the basic data model of Semantic Web. The primary goal of $\mathrm{RDF}$ is to provide standards for meta-data and explanations regarding the sources on the Web. With the help of these standards, users can be prevented from accessing irrelevant subjects since meta-data are provided regarding what the accessible information is or is about. In this way, disorientation that results from abundance of choices could be decreased.

The basic structure of RDF depends on triplet of object, quality and value. For example, the value $\mathrm{V}$ of an object $\mathrm{O}$ in quality A ('http://www.books.org/ISBN0012515866', "\$62") can be written as $\mathrm{A}(\mathrm{O}, \mathrm{V})$ or '[O] -A-> [V]' [25]. RDFs do not include any data-model relationships except for the triplet of object, quality and value. The role of RDFs provides the basic data-model of object, quality and value (OAV) for the meta-data. Like the XML data-model, the RDF data-model does not include form-related information or names. 
International Journal of Web \& Semantic Technology (IJWesT) Vol.2, No.4, October 2011

\subsubsection{RDF Schema}

RDF Schema provides syntax facility for RDFs just as XML Schema does for XML files. RDF Schema allows defining syntax that should be used for different qualities in RDFs.

\subsubsection{OWL (Web Ontology Language)}

Before mentioning OWL, which is Web Ontology Language, we should briefly discuss Ontology. Ontology is key technologies used to actualize Semantic Web. The term Ontology is also known as "ontology" in philosophy. However, in recent years, the term has increasingly been used in the areas of Semantic Web and Artificial Intelligence. Ontology in Semantic Web, which structure the information in a certain area in a way that people and computers can understand, are structures that allow sharing and reusing this information. The future of Semantic Web depends largely on the spread of ontology [26].

Semantic Web is generally discussed with respect to the three dimensions of semantic interoperability such as isolation, coexistence, and cooperation. Among these dimensions, cooperation is only possible through conceptual arrangements that would establish bridges between ontology that depend on similarities and differences [27].

Ontology allows associating the information in organized units thanks both to the hierarchical order resulting from their structures and to the open connections with other ontology. Therefore, well-structured ontology prevents information about different areas from existing together in an unorganized manner. In this way, the user does not navigate in the hypermedia subconsciously (art museum phenomenon) and is likely to avoid cognitive overload that results from being overloaded by irrelevant subjects.

Initially, languages used to develop ontology especially in the areas of science and economy was not defined as appropriate to the structured of the Web. Since these studies had long been conducted by individuals or by different groups, no certain standards were established. The OWL language created by the W3C in 2002, uniform resource identifiers (URIs), and the explanations regarding web sub-structure provided by RDF are used to add the following features to ontology [28]:

$\checkmark$ Usability by different systems

$\checkmark$ Scalability for Web needs

$\checkmark$ Compatibility with the Web standards for accessibility and international applicability

$\checkmark$ Open source and extensibility

In order to establish relationship between different ontology and classes, to ensure coordination, and to carry out various adjustments, OWL includes a number of explanations of classification and adjustment on the basis of RDF and RDF Schema.

URIs (Uniform Resource Identifiers): Uniform resource identifiers (URIs) are short character series used to define the documents, pictures, files, services, e-mail and other sources on the Web. URIs use naming schemes to make sources accessible under retrieval methods like HTTP and FTP [29]. These descriptors formulate the directives necessary to access any information on the Web. 
Table 1. Components and Features of Semantic Web and Effects on Hypermedia Bottleneck

\begin{tabular}{|l|l|l|}
\hline $\begin{array}{l}\text { Semantic Web } \\
\text { Component }\end{array}$ & Features and Benefits & e-learning Bottlenecks \\
\hline $\begin{array}{l}\text { XML(EXtensible } \\
\text { Markup }\end{array}$ & $\begin{array}{l}\text { By presenting the information in an } \\
\text { organized structure that does not tolerate } \\
\text { faults, the out-of-subject load of the learner } \\
\text { could be decreased. }\end{array}$ & $\begin{array}{l}\text { Cognitive Overload } \\
\text { (Decreasing the out-of- } \\
\text { subject load) }\end{array}$ \\
\hline $\begin{array}{l}\text { RDF } \\
\text { (Resource }\end{array}$ & $\begin{array}{l}\text { By preventing users from accessing } \\
\text { irrelevant subjects, the meta-data presented } \\
\text { regarding what the accessible information is } \\
\text { or is about can decrease disorientation that } \\
\text { Framework) }\end{array}$ & $\begin{array}{l}\text { Disorientation in } \\
\text { Hypermedia } \\
\text { (The problem of } \\
\text { abundance of choices) }\end{array}$ \\
\hline $\begin{array}{l}\text { OWL (Web } \\
\text { Ontology } \\
\text { Language) }\end{array}$ & $\begin{array}{l}\text { Ontology, thanks to their hierarchical } \\
\text { structure and their open connections with } \\
\text { other ontology, allow associating the } \\
\text { information in organized units. In this way, } \\
\text { the user does not navigate subconsciously } \\
\text { in the hypermedia (art museum } \\
\text { phenomenon) and is likely to avoid } \\
\text { cognitive overload. }\end{array}$ & $\begin{array}{l}\text { Disorientation in } \\
\text { Hypermedia } \\
\text { (Art museum } \\
\text { phenomenon) }\end{array}$ \\
\hline
\end{tabular}

To sum up, as can be seen in Table 1, XML, RDF and OWL, which are the components of Semantic Web, have important features that help overcome hypermedia bottlenecks. While XML has the potential to decrease the cognitive overload of the learner by decreasing the out-of-subject load, RDFs can help cope with the problem of disorientation in hypermedia by decreasing the problem of abundance of choices. In addition, ontology help prevent both disorientation in hypermedia and cognitive overload.

\subsection{Limitations of Semantic Web}

As is known, visualization of information in the Web environment is quite important in terms of accessing, organizing and sharing the information. However, the visualization of information formed through Semantic Web components is an area still open to research [30]. In addition, several factors prevent effective use of the potential of Semantic Web. Among these factors is the fact that Semantic Web standards like RDF and OWL are in the developmental stage and that regarding Semantic Web, the areas of logic, proof, trust, and digital signature are still in question. On the other hand, the Semantic Web components are being developed at a considerably high rate because of the projects executed by different institutions, foundations and groups throughout the world. These groups and their studies can be accessed from the website of W3C (http://www.w3.org).

\section{CONCLUSIONS AND SUGGESTIONS}

When the Semantic Web components and the features of these components are examined, it can be seen that there have been attempts to establish certain standards for structuring, sharing and accessing information. The basic reason for establishing standards is to prevent excessive complexities and disorderliness resulting from traditional Web technologies. In this way, a sample of the information designed as appropriate to the same standards will be provided, and a transition from the current complex hypermedia to a more meaningful and well-structured Web environment. In this study semantic Web components and the features of these components examined to decrease or overcome disorientation and cognitive overload in hypermedia learning environments. After the study some important features of Semantic Web components revealed that help overcome hypermedia bottlenecks: 
$\checkmark$ XML(Extensible Markup Language) for decreasing the out-of-subject load,

$\checkmark$ RDF (Resource Description Framework) for the problem of abundance of choices,

$\checkmark$ OWL (Web Ontology Language) for prevention of out-of-subject load.

The new Web environment established by the Semantic Web is considered, should decrease disorientation. The reason is that people as well as computers have important roles in the process of forming and sharing information and of giving meaning to it. Computers can associate and present information much faster and far more clearly than people can do. Use of computers especially for such routine process as searching for specific information among a large amount of information will clear away a significant amount of load on people and will decrease disorientation that results from abundance of choices. In addition, the OWL, RDF and XML structures that allow computers to understand the information units - which have gained meaning with the help of ontology - will prevent loss of time by providing the user with navigational facility. Thus, it is though that disorientation resulting from lack of background information and from over-use of time can be considerably decreased with the effective use of Semantic Web components.

Semantic Web is considered, should decrease the cognitive overload. The ontology's hierarchical structure and their open connections with other ontology, allow associating the information in organized units. And this feature provide learner to avoid cognitive overload. By presenting the information in an organized structure XML have potential to decrease the out-of-subject load. The prior condition for decreasing or preventing the hypermedia problems of Semantic Web is that all the components should be made ready for use. For this purpose, experts should define the technical sub-structures of such components as logic, proof, trust and digital signature. The components whose technical sub-structures are completed can be used in different areas. In this way, the use of Semantic Web can be spread. It is because of building semantics learning tools and utilities will open the road for the next generation learning environments [31].

Future studies can be conducted on experimental basis in order to test the advantages that are theoretically thought to be provided by Semantic Web. For example, the hypermedia in which Semantic Web components are used can be compared with the traditional hypermedia in terms of users' disorientation and cognitive load. In order to narrow down the research area, these two different hypermedia structures can also be compared in separate studies in terms of each feature (disorientation and cognitive overload).

\section{REFERENCES}

[1] Kılıç, E. ve Karadeniz, Ş. (2004). "Specifying Students; Cognitive Load and Disorientation Level in Hypermedia". Educational Administration Theory-Practice, 40, 562-579.

[2] Chen, S.Y. and Macredie, R.D. (2002). "Cognitive Styles and Hypermedia Navigation: Development of a Learning Model”. Journal of the American Society for Information Science and Technology 53 (1), 3-15.

[3] Nunes, M.B. and Fowell, S.P. (1996). "Hypermedia as an experimental learning tool: A theoretical model". Information Research News, 6(4),15-27.

[4] Neilsen, J. (1990). "Hypertext and hypermedia”. Boston: AP Professional.

[5] Dias, P., Gomes, M. J., \& Correia, A. P. (1999). "Disorientation in hypermedia environments: Mechanisms to support navigation”. Journal of Educational Computing Research, 20, 93-117.

[6] Karadeniz, Ş. (2006). "Designing usable multimedia in terms of disorientation". Y.Y.U. Journal of Faculty of Education, 3(2), 79-97

[7] Dias, P. \& Sousa, A.P. (1997). "Understanding navigation and disorientation in hypermedia learning environments". Journal of Educational Multimedia and Hypermedia, 6(2), 173-185.

[8] Beasley, R.E., \& Waugh, M.L. (1995). "Cognitive mapping architectures and hypermedia disorientation: An empirical study". Journal of Educational Multi Media and Hyper Media, 4, 239-255.

[9] Chandler, P., \& Sweller, J. (1991). "Cognitive load theory and the format of instruction". Cognition and Instruction, 8, 293-332. 
International Journal of Web \& Semantic Technology (IJWesT) Vol.2, No.4, October 2011

[10] Farrington, J. (2011). "From the Research: Myths Worth Dispelling: Seven plus or minus two". Performance Improvement Quarterly, 23(4), 113-116.

[11] Miller, G. A. (1956). "The magical number seven, plus minus two: Some limits on our capacity for processimg information”. Psychological Review, 63, 81-97.

[12] Moreno, R. (2004). "Decreasing Cognitive Load for Novice Students: Effects of Explanatory versus Corrective Feedback in Discovery-Based Multimedia". Instructional Science, 32(1), 99-113.

[13] Paas, F., Renkl, A. \& Sweller, J. (2003). "Cognitive load theory and instructional design: Recent developments". Educational Psychologist,38, 1-4.

[14] Kirschner, P. A. (2002). "Cognitive load theory: implications of cognitive load theory on the design of learning". Learning and Instruction. 12(1), 1-10.

[15] Scheiter, K., \& Gerjets, P. (2007). "Learner control in hypermedia environments”. DOI 10.1007/s10648007-9046-3.

[16] Conklin, J. (1987). "Hypertext: An Introduction and Survey”. IEEE Computer, 20 (9), 17-41.

[17] Theng, Y.L., Rigny, C., Thimbleby, H., and Jones, M. (1996). "Cognitive task graphs and executable user models for better hypertext". APCHI' 96,421 - 433, Singapore.

[18] Foss, C.L. (1989). "Tools for reading and browsing hypertext". Information Processing and Management: an International Journal, 25(4), 407-418.

[19] Demirbilek, M. (2004). "A Review of Learner Disorientation in Hypermedia Learning Environments". In C. Crawford et al. (Eds.), Proceedings of Society for Information Technology and Teacher Education International Conference 2004 (pp. 2852-2856). Chesapeake, VA: AACE.

[20] Madhu, G., Govardhan, A. and Rajinikanth, T.V. (2011). "Intelligent Semantic Web Search Engines: A Brief Survey". International journal of Web \& Semantic Technology (IJWesT), 2(1).

[21] Kurtel, K. (2008). "Future of Web: Semantic Web”. Ege Academic Review, 8 (1), 205-213.

[22] Sheth, A., Ramakrishnan, C \& Thomas, C. (2005). "Semantics for the Semantic Web: The Implicit, the Formal and the Powerful". International Journal of Semantic Web and Information Systems, 1(1), 1-18.

[23] Berners-Lee, T, Hendler, J. \& Lassila, O. (2001). "The Semantic Web". Scientific American, 284(5):3443.

[24] Dhingra, V. and Bhatia, K.K. (2011). “Towards Intelligent Information Retrieval on Web”. International Journal on Computer Science and Engineering (IJCSE), 3(4), 1721-1726.

[25] Decker, S., Harmelen, F.v., Broekstra, J. (2000). "The semantic web -on the respective roles of XML and RDF”. IEEE Internet Computing.

[26] Maedche, A., \& Staab, S. (2001). "Ontology Learning for the Semantic Web”. IEEE Intelligent Systems 16(2), 72-79.

[27] Naeve, A. (2005). "The human Semantic Web shifting from knowledge push to knowledge pull". International Journal of Semantic Web and Information Systems, 1(3), 1-30.

[28] Herman, I. (2007). "Web Ontology Language (OWL)". Retrieved 30 August, 2011 from http://www.w3.org/2004/OWL/

[29] Connolly. D. (2006). "Learning About URIs". Retrieved 08 September, 2011 from http://www.w3.org/Addressing/.

[30] Einsfeld, K., Agne, S., Deller, M., Ebert, A., Klein, B., Reuschling, C., (2006). "Dynamic Visualization and Navigation of Semantic Virtual Environments". Tenth International Conference on Information Visualization (IV'06).

[31] Balog-Crisan, R., Roxin, I. \& Smeureanu, I. (2008). “e-Learning platforms for Semantic Web”. In J. Luca $\&$ E. Weippl (Eds.), Proceedings of World Conference on Educational Multimedia, Hypermedia and Telecommunications 2008 (pp. 1695-1699). Chesapeake, VA: AACE. 
International Journal of Web \& Semantic Technology (IJWesT) Vol.2, No.4, October 2011

\section{Authors}

Mehmet FIRAT is Research Assistant in Department of Distance Education, Faculty of Open Education at Anadolu University. The researcher continues his Ph.D education at the Department of Computer Education and Instructional Technologies.

Abdullah KUZU is Associate Professor Doctor in Department of Computer Education and Instructional Technology at Anadolu University. He has a Ph.D. in educational technology. He conducts action research projects on mobile technologies for handicapped students, works on designing multimedia learning environments, interactive animations and educational games, and offers courses on current trends and issues in instructional technology, research problems in instructional technology, action research and qualitative research methods.
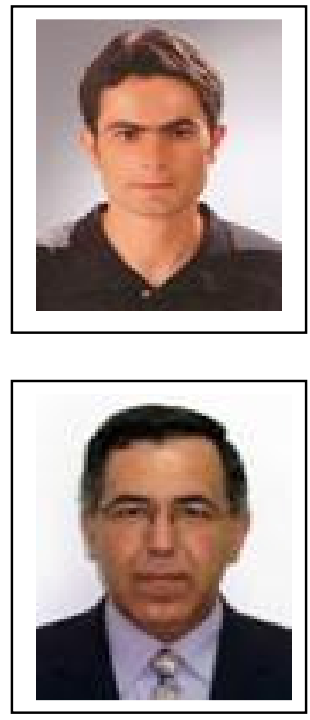